\title{
Circuit
}

Musiques contemporaines

\section{Avant-propos : la conjonction « et »}

\section{Maxime McKinley}

Volume 26, numéro 3, 2016

Musiques aux limites de l'image

Images at the Limits of Music

URI : https://id.erudit.org/iderudit/1038512ar

DOI : https://doi.org/10.7202/1038512ar

Aller au sommaire du numéro

Éditeur(s)

Les Presses de l’Université de Montréal

ISSN

1183-1693 (imprimé)

1488-9692 (numérique)

Découvrir la revue

Citer ce document

McKinley, M. (2016). Avant-propos : la conjonction « et ». Circuit, 26(3), 5-6.

https://doi.org/10.7202/1038512ar

Ce document est protégé par la loi sur le droit d'auteur. L'utilisation des services d'Érudit (y compris la reproduction) est assujettie à sa politique d'utilisation que vous pouvez consulter en ligne.

https://apropos.erudit.org/fr/usagers/politique-dutilisation/
Cet article est diffusé et préservé par Érudit.

Érudit est un consortium interuniversitaire sans but lucratif composé de l'Université de Montréal, l'Université Laval et l'Université du Québec à Montréal. Il a pour mission la promotion et la valorisation de la recherche. https://www.erudit.org/fr/ 


\section{Avant-propos : la conjonction « et»}

Maxime McKinley

Ce numéro portant sur les musiques de création et les images en mouvements est une belle opportunité d'évoquer une conjonction qui, à Circuit, nous est chère. Il s'agit de la conjonction «et», telle qu'en parle Gilles Deleuze (philosophe cinéphile s'il en est) au sujet du cinéma de Jean-Luc Godard ${ }^{1}$. Le faux raccord entre deux plans met en jeu le battement de la séparation et du contact: en somme, de la relation. C'est, paradoxalement, à leurs frontières que deux plans se touchent. Parfois, ce phénomène s'applique aussi aux rencontres interdisciplinaires. Si nous tentions une typologie des numéros de Circuit, le rôle de ce «et» serait incontournable.

Le catalogue de la revue est, en effet, tissé de divers fils rouges. On y trouve des portraits multiples - souvent générationnels -, à l'instar du numéro «Autoportraits: Montréal, l'après 67» (vol. 8, $\mathrm{n}^{\circ}$ 1). Le prochain numéro, dirigé par Simon Bertrand, s’inscrira d'ailleurs dans cette catégorie. On trouve également des monographies sur des compositeurs québécois, notamment tous ceux de la Série hommage chapeautée par la Société de musique contemporaine du Québec (SMCQ): Claude Vivier (vol. 18, nº $3^{2}$ ), Gilles Tremblay (vol. 20, $n^{\circ} 3^{3}$ ), Ana Sokolović (vol. 22, $n^{\circ} 3$ ), Denis Gougeon (vol. 24, $n^{\circ}$ ), John Rea (vol. 26, $n^{\circ} 1^{4}$ ) et, l'an prochain, José Evangelista. D'autres monographies ont été consacrées à des compositeurs contemporains internationaux nouvellement devenus, ou en voie de devenir, des classiques: pensons, par exemple, à Iannis Xenakis (vol. 5, nº 2), Fausto Romitelli (vol. 24, $\mathrm{n}^{\circ} 3$ ) et John Zorn (vol. 25, $\mathrm{n}^{\circ}$ 3). La revue s'intéresse également à des thématiques plus ou moins générales telles que la commande d'œuvre (vol. 26, n² 2), la notation musicale (vol. 25, $\mathrm{n}^{\circ} 1$ ), la mise à jour et/ou la contemporanéité des supports médiatiques en musique contemporaine (vol. $23, n^{\circ} 2^{5}$ ), pour ne citer que quelques exemples récents. À cela, nous pourrions ajouter des numéros
1. Voir, par exemple: Gilles Deleuze (1985), Cinéma 2: l'image-temps, Paris, Minuit, p. 242.

5. Voir aussi : vol. 16, $n^{\circ} 3$. 
6. Circuit et Intermédialités produisent ensemble des balados depuis 2014. Le premier porte sur "La musique des objets", le deuxième sur "L'autre Gould " et le dernier sur "L'archive en ligne de la troupe de théâtre Dora Wasserman". La série est disponible pour écoute sur la web radio culturelle Globe sonore:

$<$ www.globesonore.org $>$ soulignant des anniversaires, qui portent sur des débats spécifiques, et d'autres catégories encore.

La présente livraison, codirigée par notre directrice administrative et secrétaire de rédaction, Solenn Hellégouarch, et son ancien codirecteur de thèse, Serge Cardinal, s'inscrit pour sa part dans une sous-collection de Circuit que nous pourrions nommer la série "Conjonction "et" ». Notre amitié avec la revue Intermédialités - dont témoignent notre numéro sur Les arts de la synchronisation (vol. 22, $\mathrm{n}^{\circ}$ ) et la série de balados Contrepoints ${ }^{6}$ - dit assez notre intérêt pour les interlocuteurs (a priori) non musicaux parmi les disciplines artistiques et intellectuelles gravitant autour de la musique et réciproquement. Musique et quoi? Jusqu'à maintenant: écologie (vol. 25, nº 2), science (vol. 24, $n^{\circ}$ 2), spiritualité (vol. 21, $\mathrm{n}^{\circ}$ 2), féminisme (vol. 19, nº 2), historiogra-

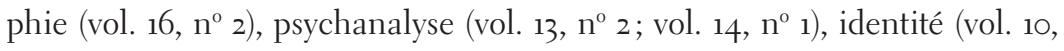
$\mathrm{n}^{\circ} 2$; vol. $15, \mathrm{n}^{\circ} 2$ ), etc. Aujourd'hui, nous ajoutons les images en mouvements à ce «et» multiple. Et parions que la liste ne s’arrêtera pas là !

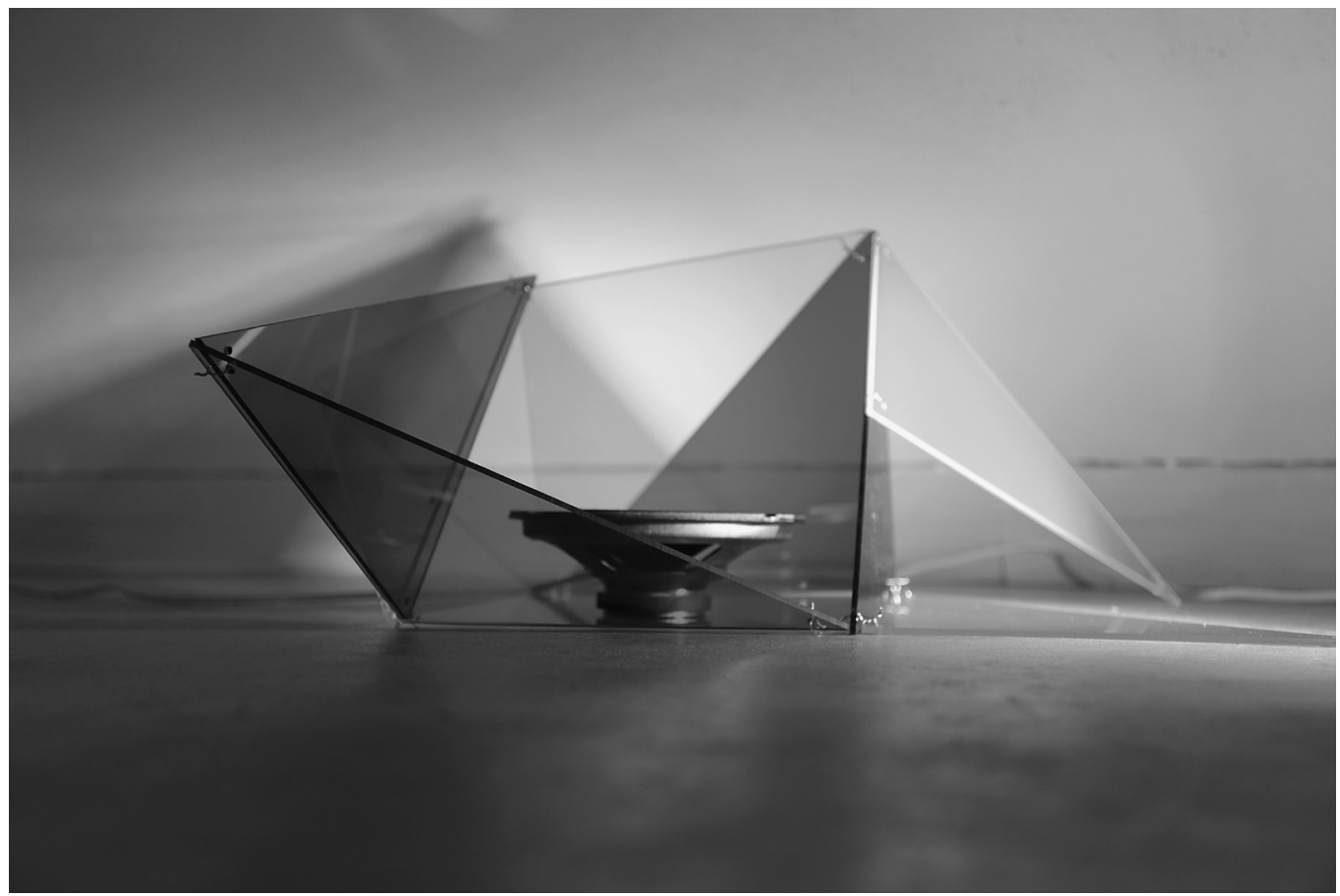

Steve Roden, Gradual Small Fires and A Bowl of Resonant Milk, 2012. Plexiglass de couleur, bois, haut-parleurs, composition sonore. Creative Media Center, Université de Hong Kong, Chine. 